\title{
BRIDGING THE CITY: CONNECTING ART, PERFORMANCE DESIGN, ENVIRONMENT AND EDUCATION
}

\author{
Marija Griniuk \\ The University of Lapland, Finland
}

\begin{abstract}
This study explores knotworks and networks within art, participatory performance design, the environment and education specialists and institutions within the case-project "Nomadic Radical Academy", realised in 2019 and 2020. The novelty of the research lies in its investigation of how international collaborations impact the performance pedagogy project at the local level. The project bridged a wide spectrum of actors in order to design an interactive space and participatory infrastructure involving a diverse variety of stakeholders. The projects were created by the author of this paper and involved the art venue Gallery Meno Parkas in Kaunas, local Kaunas schools and environment-friendly local art initiatives, families in Kaunas, Kaunas Municipality, The Lithuanian Council for Culture, a performance designer and international artists from the Baltic-Nordic region. The author created the performative milieu in the gallery space with the intention of educating children and young people about the environment and climate change through performance pedagogy methods. The research question is as follows: How are the knotworks and networks created during the planning and realisation of the international performance pedagogy project, and how do they target the local community and influence projects locally in real-time? The study materials were collected by arts-based methods and analysed by utilising reflexive research. The data collected during the planning and implementation phases are the author's notes and reflections, notes from feedback and discussions with the involved artists and photos and videos. This research can be valuable to educators, performance designers and artists interested in knotwork- and networkbuilding. This research focused on the planning and realisation of the project by involving international performance professionals in site-specific projects designed for local communities.
\end{abstract}

Keywords: arts-based research, knotworks, networks, participatory infrastructure, participatory performance design, performance pedagogy.

\section{Introduction}

This article explores connections formed by the author, conceptualised as knotworks and networks. This was done to realise the participatory performance pedagogy project within the author's local community, which aims to educate children and young people about responsible eco-friendly behaviours and responsible consumption. This study is the part of the author's doctoral research, 
which is themed around the new format of performance art documentation using biometric data collected from the performing body. This is a collaborative process involving international peers-performance artists into the projects locally. This article analyses collaborations between the performance artists and organisations. The examples are the author's projects, for which collaborations were at the core. The Nomadic Radical Academy: The Good, The Bad and The Art 2020 involved the following contributors: Dr. Julia Kurek (PL), Evelina Šimkute (LT), PhD Cand. Rait Rosin (EST), Tue Brisson Mosich (DK / LT) \& Julija Rukanskaitè (LT/SE), PhD Cand. Linda Teikmane (LV) and Kaspar Aus (EST), among others. The project was realised with the support of the Gallery Meno Parkas, Kaunas Municipality and The Lithuanian Council for Culture. It builds upon the first test event, The Nomadic Radical Academy for the Climate Change Awareness in 2019. This event involved Tue Brisson Mosich (DK/LT), Nanna Ylönen (FIN), Marta Gil (SE), Sanna Blennow (SE), Rikke Goldbech (DK), Anne-Louise Knudsen (DK), Anders Werdelin (DK), and Dr Adomas Danusevičius (LT/DK). Collaborations were with Kaunas-based Lithuanian artists and initiatives-which involved Evelina Šimkute, Šilainių Sodai and Raimondas Binkauskas, along with others through the support of the Gallery Meno Parkas, which provided the venue and was self-funded by the project's author. The research aim is to analyse the collaborations (identified as knotworks and networks) within the case study project and their impact on it. The methods employed to do this are arts-based research (Leavy, 2015) (in the phase of the material gathering) and the reflexive research (Weber, 2004) (in the phase of reflecting on the collected data).

\section{Theory and Previous Research}

The theory and concepts used within this study are performance pedagogy, knotworks, networks, participatory infrastructure and arts-based research. Infrastructure is explained as the interrelations connecting venues, technologies and practices (Karasti, 2014). In this article, the term 'participatory infrastructure' is used when analysing the provided case, which underlines the active involvement of all the stakeholders in the project. Participatory infrastructure is often presented as a horizontal and local process (Bødker, Dindler \& Iversen, 2017; Star \& Ruhleder, 1996; Star \& Bowker, 2002). In the presented case study, it was considered the meeting point between Northern European experts and the local experts, institutions and community targeted at the local process. In this way, as in the reviewed literature sources, participatory infrastructure places institutions, users and facilitators into collaborative relationships and arenas of interconnections (Kensing \& Blomberg, 1998; Gärtner \& Wagner, 1996).

The term 'knotworks' refers to the temporary networks created for the duration of the project (Bødker et al., 2017). Meanwhile, networks are the 
durational connections that immerse into the project from the author's previous collaborations; alternatively, they might have a speculative durational impact on the author's practice and the community (Bødker et al., 2017). Performance pedagogy is theoretically explained as a pedagogy that involves performativity and the performative behaviour of the teacher or facilitator (Pineau, 1994; Griniuk, 2020). In the learning environment within this case study, performance pedagogy is grounded in Fluxus pedagogy (Griniuk, 2020). The participatory performance pedagogy design described in this article falls under the same definition as the discipline of performance design. According to performance scholar Richard Schechner (1977), performance can be defined as a wide spectrum of artistic activities that involve space, time, the human body, and an audience. Thus, in the described cases, participatory performance pedagogy is an extended term for performance as specified by the author.

\section{Methods and Materials}

International networks and knotworks that manifested through a performance pedagogy project within the local community co-shaped and influenced the project as it unfolded on site. Arts-based research (ABR) is theorised as a data-collection method with art at its core (Barone \& Eisner, 2012; Leavy, 2015). In the studied cases, performance as art was a means for gathering data at all the stages of project planning (i.e. when designing the project with the involved stakeholders) and implementation. Participatory and dialogue-based art is at the core of ABR (Hammersley and Knowles, 2016), as the dialogue can be understood as the artist's way of navigating and developing knotworks and networks in order to bring the project into the local community.

Data collection was implemented utilising ABR, with performance art used as a means to create and collect the materials. The method of reflecting on the research data is based on the author's experience and previous practices within the field of performance. This method is defined as reflexive research by sociologist and scientist Ron Weber (2003), according to whom the reflexive researcher belongs to the field of his or her study and reflects on data from the perspective of this experience. The author of this paper has been involved in collaborations (knotworks and networks) within the field of performance pedagogy and education during the last decade-for example within the longitudinal project by the author of this paper "BiteVilnius" (BiteVilnius, 2020). The data collected during the projects in 2019 and 2020 were photos and videos, notes from discussions with co-facilitators, and facilitator-observer notes. These materials were collected and organised into data folders, each of which was labelled based on the date of the corresponding part of the event. 


\section{The Cases}

Over the past decade, the author has been working in the field of participatory performance. Her specific interest in performance as the pedagogical means aimed at children and youth, combined with her interest and passion for a clean environment and responsible consumption, has resulted in the durational collaborative performative activities. This was the particular format of The Nomadic Radical Academy. The first project The Nomadic Radical Academy for Climate Change Awareness 2019 was implemented at Gallery Meno Parkas in Kaunas in the format of three days of performances and two weeks of installation space at the gallery, which contained the residue from the performative activity and its video documentation. The theme of this project was a post-apocalyptic world impacted by climate change. The installation contained shantytown constructions, with tents inhabited by the artists and children during the project. There, performative activities took place. The participants were children and their families. When entering the installation at the gallery space, children occupied the tents, which were pre-built from recycled and found materials. They were using them during the breaks. The performative actions were divided into 4-5 segments and the children and involved grown-ups were participating in 1-2 hour sessions with the facilitators. The thematic framework was centred around climate change and responsible behaviour in natural environments.

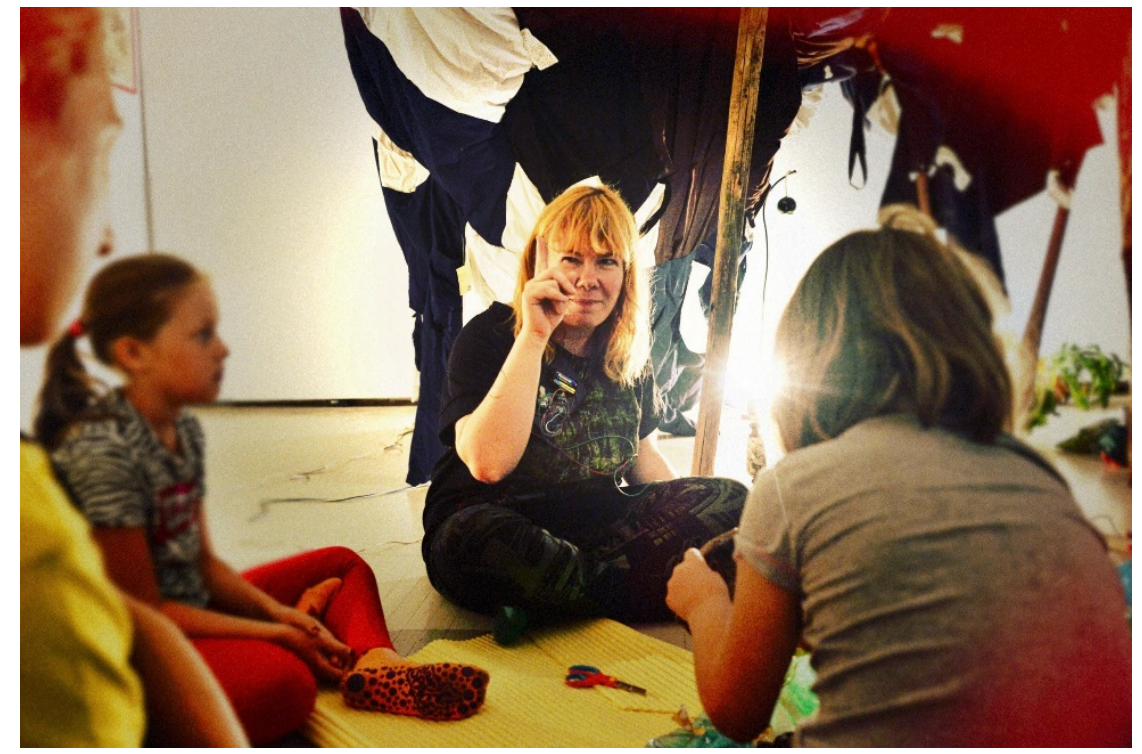

Figure 1 The Nomadic Radical Academy for Climate Change Awareness 2019 (Photo: Antanas Untidy)

The second edition of the project took place in August 2020 at the Gallery Meno Parkas and occupied the entire three floors of the gallery. The activity was 
scheduled over nine days, during which the children worked with the main facilitator (the author of this article). Guests were present for nine hours each day. The overwhelmingly intensive performance environment stretched over the gallery spaces, outdoor public areas near the gallery, and the inner yard of the gallery, which was the collective space of all the involved neighbourhoods. The performance art program was a compilation of short performance exercises and live activity with breaks in between them. The program consisted of workshops and participatory performances, which involved the children. The activities had variable duration - from 20 minutes to 1,5 hours. The theme of all the workshops and performances was transcorporeality, meaning the combination of human, non-human bodies and more than human bodies in the socio-cultural context. The children were encouraged to think about human and nature relations and interhuman connections. The participants comprised over 20 local children (7-14 y.o.) from schools in the Kaunas municipality, one of whom was a disabled child with special needs. The children participated voluntarily on the basis of the open call application. A few facilitators-volunteers were involved for periods ranging from a few hours to a few days. All volunteers were artists, environmental activists and gymnasium students from the local Kaunas community.

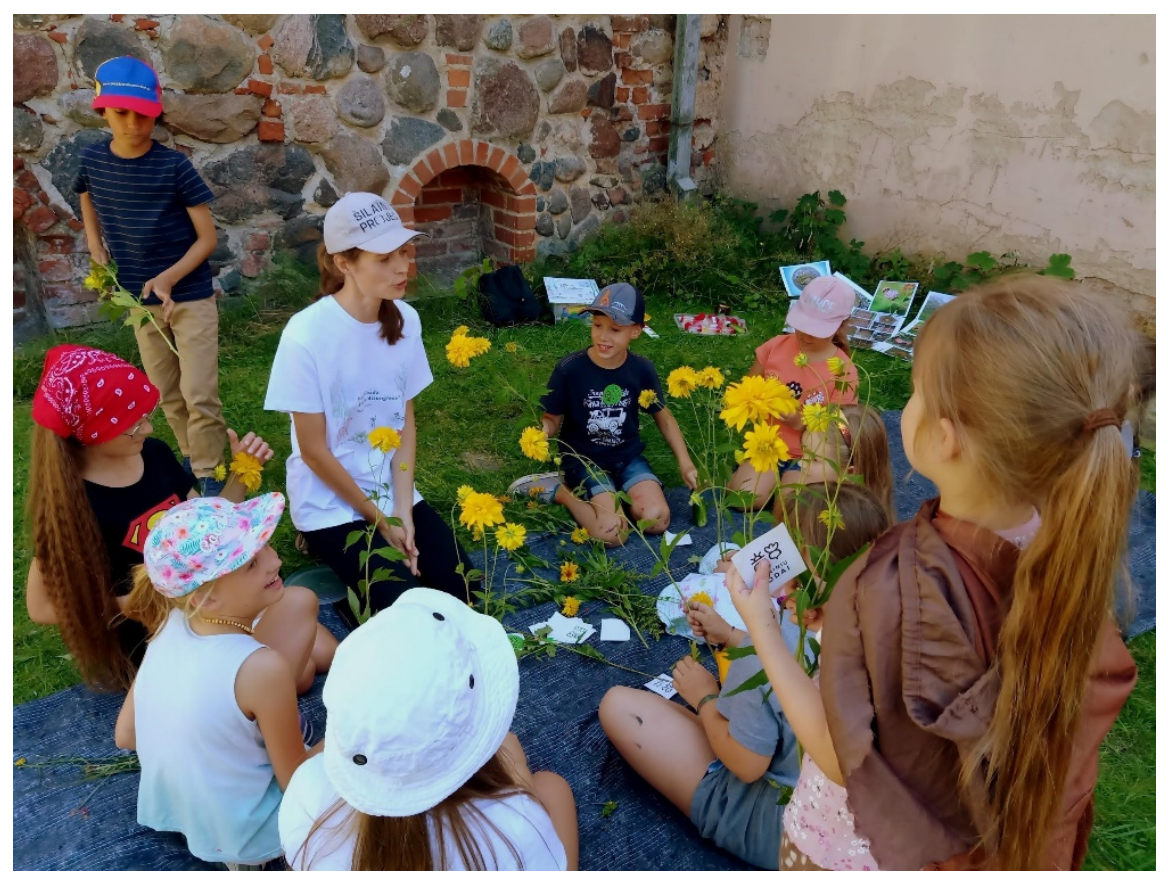

Figure 2 The Nomadic Radical Academy session facilitated by local artist and activist Evelina Šimkutè in 2020 (Photo: Raminta Jodikaitytè) 


\section{Research Results}

This paper distinguishes the main research results, which are based on the two analysed case projects, as well as literature sources and previous research exploring the concepts of networks and knotworks across a wide scale of participatory design. Within this paper, these concepts are specified particularly for the analysis of the participatory performance pedagogy project as the artsbased research case. Within the design of projects such as The Nomadic Radical Academy, interhuman connections are speculatively intertwined in the planning phase. In this phase, the major insights were related to the desired outcome via interpersonal impact and empathic meaning-making towards nature and human behaviour. The international artists met within the local community and worked towards deepening their knowledge of the local natural environments and discussing how individuals could change their behaviour to become more friendly to nature. One of the examples is the artistic action towards re-thinking the concept of "trash" and the responsibility to recycle, which has been practised in Lithuania on the municipal level only over the past few years.

The aim of involving international performance art professionals is to connect the participants by artistic means, empathically, to the concept of responsible behaviours. This empathic connection is targeted to reach the deeper levels of critical thinking and foster reflexive pedagogy (Rothman, 2014) and the performance pedagogy (Griniuk, 2020) aspects involved as the core dialogical tools. The speculations within participatory performance pedagogy design during the planning phase deal with how the projects will unfold. These speculations are in constant flux and interchanging as the correspondence and meetings with all the involved stakeholders happen and as new stakeholders get more deeply involved in the project by finalising their ideas for contributions. As theoretically explained, this phase is the backstage area of participatory performance pedagogy design, and it consists in the scope of "messy activities that occur before" the project is launched (Bødker et al., 2017). The contributions should be as thematic as possible and free as they can be not to deform the artists' individual practices. The artists are not expected to do anything that they do not usually do; they are expected to enrich the project by their practise-based knowledge.

The final shapes of the projects are presented in real-time as the participants arrive and influence the space of the project. The interhuman connectionsbetween the venue representatives and the artists, between the artists and between the artists and the children involved from the very first day until the project endsco-create the framework of the performative actions. Some artists, exemplified by Kaspar Aus, arrived at the performative space and physically stayed for the entire project, interacting with the children and inviting them into their improvisations. Some artists very clearly identified when they would and would not be present, or 
"on stage", in the space. Both types of contributions were welcome and valued highly as this kind of variety of dynamics is at the core of the project. In other words, variations among the artists' contributions were expected. The project was never the same during its implementation as it was during its design. There were, however, always expectations of variations. The local impact was observed on a daily basis by spectating the spontaneous actions within the project. Moreover, the longitudinal impact on the local community is impossible to track, as the connections with the participants are agreed upon to take place only during the project. So, the research question in this article can be answered only by utilising knowledge from the planning phases and the phases of the implementation of the two cases.

As soon as the collaborations are embodied in the site of the event, the author's responsibility for the project takes the form of co-responsibility of all involved parts. Co-responsibility becomes the common ground of negotiations and shapings of the project, be it without funding (as in the case of 2019) or with extensive funding from institutions (as in 2020). Both projects involved very different target groups, though both were representative of the Kaunas community. The participants of the projects-in the present case, young people and children - can be described as knotworks or temporary connections that highly influence the project on-site. However, one participating child attended both years. Participants as knotworks are at the core of the project, and it unfolds in a particular, improvised way, depending on who is involved and how the involved parts interconnect.

The participatory performance pedagogy design in both of the case projects occurred through individual online communication between the author of this research and the involved artists. In 2019 an attempt to create a collaborative communication channel did not succeed, so the most effective way to communicate was to have individual discussions during the planning phases. Both years, the project had the primary goal of gathering professionals from Northern Europe who deal with environmental issues and art.

The primary goal was for knotworks within the project to become networks at a longitudinal scale. Such network-building is aimed at uniting professionals of similar fields of interest and by means of collaborations within one project to empower the field of work in further speculative development if the networks would last. Analysing from the perspective of the concept of front stage and backstage (Goffman, 1959), the article suggests that knotworks are part of the front stage, as the temporary project-based collaborations are the highlights of the project as it unfolds. The project is spectated from the actual beginning to the end, and all the turns, improvisations or spontaneous actions caused by various temporary connections become the active part of the project's content, which is seen in real-time. The author gathered four long-term collaborators (Kaspar Aus, 
PhD Candidate Rait Rosin, Tue Brisson Mosich, and Dr Adomas Danusevičius) with whom mutual projects had taken place during the last five years and the artists knew each other very well. Anyway, the majority of involved professionals were unfamiliar with each other and to the author.

Cooperative prototyping sessions that took place on-site (Bødker et al., 2017) can be seen as co-installing the performance space, when artists bring and introduce their artworks and art objects into the space, always happening on-site shortly prior to launching the projects. Prototyping here is seen as co-visioning and co-creating the final look of the space where the interactions happen as the participants arrive. These on-site cooperative prototyping sessions (Bødker et al., 2017) involved intensive discussion and feedback events with the possibility to learn each other's practices and see how these practices find their place within the project. These were the first in-person meetings between all involved artists upon their arrivals into the gallery. However, due to the pressure of the short time before the launch of the project, these meetings were often quite unorganised and short and were mostly aimed at finding the right locations (from the perspective of the artists and the author) for all the installation elements and ensuring that all technology worked. This spontaneity was the potential threshold where the involved artists could enter the networks and speculatively learn about future collaborators practices.

Interestingly, in the previous author's projects, such as BiteVilnius (BiteVilnius, 2020), some collaborations emerged immediately after the projects, and a few artists are still collaborating internationally on a longitudinal scale of more than five years. In the Nomadic Radical Academy, the phase of meeting and prototyping the space on-site often continued through ongoing informal discussions during the project on how different elements impact the interactions. For example, the artwork by Anders Werdelin left black spots on the children's bodies as they would try to touch it. These interactions by the children with the installation element ranged from unintended incidents to the purposeful creation of circles and ornaments on the bodies of the children.

The other dimension of the participatory performance pedagogy design aimed at interinstitutional knotworking and networking within preparations and negotiations regarding the fundamental outcome, especially in 2020, when the project was fully funded. As earlier theoretically explained, the design process unfolds by the front stage and backstage (Goffman, 1959), which is even more clear within the interorganizational connections. The messy, negotiation-based and conflict-prone process (Bødker et al., 2017) as the core of the participatory infrastructure started at the fundraising phase, especially in 2020, when this process involved two additional organisations (i.e. the exhibition venue and the Municipality and The Council for Culture). The applications needed to meet the guidelines of the funding open calls, and each of the applications reshaped the 
project into those guidelines, which in the realisation phase of the project became the active projects' content parts.

Each of these organisations provided the material base for the project to happen, which, in cases of one-time project support, are defined as knotworks (Bødker et al., 2017). In the case of the collaboration with the Gallery Meno Parkas, it can be defined as a network (Bødker et al., 2017) due to the author's longitudinal collaboration with this venue. Each of the knotwork and network members has expectations of what impact the project should have and how intensive or passive the interconnections between the involved stakeholders should be. Active involvement, for example, could be a visit from the representative of the municipality during the project in 2020, as the municipality had local goals and explained the project to the local families whose children attended local schools. The representative of the municipality supervised the process in person.

The author of the project, using the provided material base, is expected to deliver a project that satisfies all expectations. During the documentation phase, an image of the past event is created, which captures the emotions and reactions shown through the interhuman communications of the real-time activities. The impact of the knotworks is captured and delivered as the image of the participatory performance pedagogy project targeted at the local community. Meanwhile, networks remain an invisible and immeasurable speculative aspect of the project's outcome. Speculatively, the messy process of performance design benefits network-building and deepens the possibilities (or impossibilities) for future collaborations between the involved stakeholders. The backstage is oriented towards activities and processes that tie the project together:

"Networks and knotworks provide a way to discuss the back stage activities and also parts of an infrastructure in which ideas, technologies, and organisational arrangements are developed and appropriated. However, to understand the significance of these constellations beyond their immediate settings, it is necessary to look at how processes and outcomes are extended over time." (Bødker et al., 2017, p. 252)

In the case projects, the networks and knotworks within the process of the project's design and implementation (specifically in the conceptual framework of the backstage) provided an arena for empowering the project's author and venues. The autonomy in the case of The Nomadic Radical Academy in 2019 and 2020 is seen in the local embodiment of the project, and it has an immediate effect. This effect is due to front stage factors (the real-time experience of the project by all involved and the publicity of the project) as well as backstage factors (the experience of what works and what does not work within the project locally). The backstage factors might differ significantly depending on what location the project takes, and so the analysed processes are applicable primarily within the 
same or similar local contexts. Relational agency (Bødker et al., 2017), as a concept uniting all involved stakeholders into collaborative processes, is applicable locally based on the front stage and backstage and can be utilised within the (speculative) next edition of the project.

Understanding the possible obstacles and opportunities of real-time actions (both in planning and implementation phases) might make the process easier over time. "Knotworks and networks describe the constellations that emerge through infrastructuring, [while] relational agency describes the stakeholders' capacity to engage in these processes” (Bødker et al., 2017, p.252).

The relational agency across the vertical power relations was not in focus during the development and execution of the project, however it did become apparent that there were issues relating to this that were never addressed, which affected the project. Thus, future projects and research might give a higher priority to these types of agency and relations. It is essential to envision the perspectives of the project and enhance the motivation of the author and the art venue, as well as that of the involved professionals and organisations to practice, participate, and support participatory performance pedagogy processes within communities.

\section{Conclusions}

The study explored the impact of international knotworks and networks on a locally targeted participatory performance pedagogy project. In the performance design phase, the online communication processes with all involved professionals impacted the spontaneity of the site-specific involvement upon their arrival into the project venue. During this phase, the first physical meeting of the stakeholders occurred, which intertwined and shaped the project as it unfolded. The front stage of the project was the action (which was in constant flux) and is directly emerging from the knotworks involved in the project. The front stage entered the documentation material and became the image of the past performance, while the backstage of the project evolved into collaborations between the involved parts. The co-responsibility for the impact of the project at the local level and the responsibility of the author of the project for the outcome and collaborations of the involved stakeholders influenced the development of the project. Knotworks can be developed into networks by fostering ongoing communication and a potentially longitudinal vision of collaborations as a metaphorical weaving of the idea behind the project into future perspectives. The present research can be used by professionals working on projects that involve inviting international performance artists to take part in local site-specific projects. 
SOCIETY. INTEGRATION. EDUCATION

Proceedings of the International Scientific Conference. Volume IV, May $28^{\text {th }}-29^{\text {th }}$, 2021. 528-538

\section{Acknowledgements}

This article was written during the residency period at Vindbyholtgård Refugium (Leif Hasle's Fond, Denmark) in 2020. The project The Nomadic Radical Academy: The Good, The Bad and The Art 2020 was realised with the support of the Gallery Meno Parkas, Kaunas Municipality and the Lithuanian Council for Culture (Lithuania). Thanks to The University of Lapland.

\section{References}

Barone, T., Eisner, E. (2012). Arts based research. Los Angeles: Sage.

BiteVilnius. (2020). Retrieved from www.bitevilnius.nu

Bødker, S., Dindler, C., \& Iversen, O. S. (2017). Tying knots: Participatory infrastructuring at work. Computer Supported Cooperative Work (CSCW), 26(1-2), 245-273. doi: 10.1007/s10606-017-9268-y

Borderlands of Design and Access for Large Information Spaces. (n.d.). Information Systems Research, 7(11), 111-134. doi: 10.1287/isre.7.1.111

Gärtner, J., Wagner I. (1996). Mapping Actors and Agendas: Political Frameworks of Systems Design and Participation. Human-Computer Interaction, 11, 187-214. doi: 10.1207/s15327051hci1103_1

Griniuk, M. (2020) Performance Pedagogy: Performing Fluxus Pedagogy in a Contemporary Lithuanian Context, Acta Paedagogica Vilnensia, 440, 152-163. doi: 10.15388/ActPaed.44.11.

Goffman, E. (1959). The presentation of self in everyday life. Garden City, NY: Doubleday.

Hammersley, J., \& Knowles, R. V. (2016). The Dialogic: art work as method. In National Association of Fine Art Educators (NAFAE) Fine Art Research Network Symposium. National Association of Fine Art Educators.

Karasti, H. (2014). Infrastructuring in participatory design. In Proceedings of the 13th Participatory Design Conference: Research Papers-Volume 1, 141-150.

Kensing, F. \& Blomberg J., (1998). Participatory design: Issues and concerns. Computer Supported Cooperative Work, 7, 167-185. doi: 10.1023/A:1008689307411

Leavy, P. (2015). Method meets art. arts-based research practice (2nd ed.). New York: The Guilford Press.

Pineau, E. L. (1994). Teaching is performance: Reconceptualising a problematic metaphor. American Educational Research Journal, 31(1), 3-25. doi: 10.3102/0002 8312031001003.

Rothman, J. (2014). Reflexive pedagogy: Teaching and learning in peace and conflict studies. Conflict Resolution Quarterly, 32(2), 109-128. doi: 10.1002/crq.21107

Schechner, R. (1977). Essays on Performance Theory: 1970-1976. New York: Drama Book Specialists.

Star, S. L. \& Bowker G. C., (2002). How to infrastructure. In L.A. Lievrouw and S. Livingstone (Eds): The Handbook of New Media, 151-162. London: SAGE,

Star, S. L. \& Ruhleder K., (1996). Steps toward an Ecology of Infrastructure:

Weber, R. (2003). Editor's comments: The reflexive researcher. MIS Quarterly, 27(4), v. doi: $10.2307 / 30036546$ 